\title{
Pharmacists' Perceptions of Handling Antimicrobial Resistance (AMR): A Case Study in Saudi Arabia
}

\author{
Zahra AL Qamariat (ID \\ Dalia Almaghaslah (iD) ${ }^{2}$ \\ 'Intesive Care Unite, First Health Cluster \\ in Eastern Province, Dammam Health \\ Network, Dammam, Saudi Arabia; \\ ${ }^{2}$ Department of Clinical Pharmacy, King \\ Khalid University, Abha, Saudi Arabia
}

Introduction: Saudi Arabia is one of the countries facing the emergence of antimicrobial resistance (AMR). The pharmacist is an important stakeholder in the healthcare system who plays a crucial role in avoiding AMR and implementing antimicrobial stewardship (AMS). Methods: A cross-sectional design was used in this study. The online questionnaire collected data regarding the enablers that have helped in preparing pharmacists to handle AMR and the barriers faced by pharmacy personnel in handling AMR, as well as the strategies used to overcome the identified barriers.

Results: A total of 109 participants were included in the study. Just under two thirds (62.4\%) of participants were female and the majority $(70.6 \%)$ worked as pharmacists. Just under half (41.7\%) had between 6 and 10 years of work experience. Three quarters $(74.3 \%)$ had antimicrobial stewardship in place and around the same number (73.4\%) were involved in handling infectious disease management during the COVID-19 pandemic. Pharmacists have found that preparatory items/tasks, pharmacy college curriculum, pharmacy rotation, years of experience and self-education related to AMR handling to be natural, with a mean of 3.2. The participants found all the barriers - insufficient background, in site education and training, limited time, limited CPD activities, limited educational tools and no free access to relevant clinical journals to be relevant, with a mean of 4.05. The participants found all the enablers - CPD activities, funded educational programs, allowing time for self-education, accessible educational resources and tools, annual evolution of competencies - to be relevant, with a mean of 4.12.

Conclusion: The study concluded that the barriers preventing the handling of AMR could be overcome through allowing pharmacists more time for self-directed continuous education, providing access to tools and online educational resources, and offering pharmacists funded courses to equip them with the knowledge, skills and competencies needed to handle AMR.

Keywords: antimicrobial resistance, pharmacists, AMR, Saudi Arabia, barriers, enablers

\section{Introduction}

Antimicrobial resistance (AMR) is an emergent global threat with a negative impact on the health system and the wider community. It is expected to be the reason for ten million deaths per year by 2050. Thus, it has to be addressed seriously as a global issue to be managed and controlled. ${ }^{1}$ In 2015, the World Health Organization (WHO) developed a global action plan on AMR, based on five objectives. The objectives may be summarized as using communication, education and training to increase understanding of AMR, empowering knowledge and evidence-based treatments, using surveillance and research, activating effective sanitation, hygiene and infection prevention measures to minimize infection risk, managing antimicrobial use and, finally, developing a strategy which allows for sustainable investment covering
Correspondence: Dalia Almaghaslah Department of Clinical Pharmacy, King Khalid University, PO BOX 1882, Abha, 6144I, Saudi Arabia

Tel +966563885832

Email damoazle@kku.edu.sa 
global needs in addition to investment for new interventions. The Kingdom of Saudi Arabia (KSA) is one of the countries facing the emergence of AMR, especially with gram negative bacilli (GNB). For example, the prevalence of carbapenem resistance GNB as well as Acinetobacter baumannii has dramatically increased over recent years. One study in Riyadh compared susceptibilities of Acinetobacter baumannii to carbapenem and showed that the susceptibility range had reduced from $64-81.2 \%$ in 2006 to $8.3-11 \%$ in 2012 . For this reason, the KSA developed a national action plan in 2017, based on the WHO's objectives to combat AMR. ${ }^{2}$ Some strategies that have been activated by the plan proven its impacts. For example, one study showed that when regulations were listed and implanted by the Saudi Ministry of Health $(\mathrm{MoH})$ to control antimicrobial sales in community pharmacies by restricting sale without prescription, this resulted in 50\% antimicrobial sale reduction in 2018 compared with 2017. ${ }^{3}$ Also, according to the WHO, the understanding of AMR among healthcare professionals, together with training and education, may help tremendously in combatting AMR and reducing its consequences. ${ }^{1}$ The Saudi $\mathrm{MoH}$ has implanted this through activating an AMR E Learning educational program and recommending adding AMR and related topics to undergraduate curricula for human health professionals, animal health professionals, and food industry and agriculture professionals. ${ }^{2}$ The pharmacist is an important stakeholder in the healthcare system, who plays a crucial role in avoiding AMR and implementing antimicrobial stewardship (AMS), which have both been proposed as vital. ${ }^{4}$ Thus, the pharmacist's attitude, knowledge and perception of AMR and AMS have been studied. For example, a Malaysian multicenter cross-sectional survey the assessed knowledge and perceptions of pharmacists regarding antibiotic use and resistance. It showed that even basic questions were correctly answered by a large number of pharmacists - questions relating to the clinical use of antibiotics were answered significantly incorrectly $(\mathrm{p}<0.001)$. The majority of pharmacists perceived that polypharmacy and the use of broad-spectrum antibiotics caused AMR. Also, pharmacists perceived that the appropriate use of antibiotics was a responsibility shared between pharmacists and clinicians. However, less than $50 \%$ perceived over-use of antibiotics in their hospitals. ${ }^{5}$ Also, a study conducted in Australian and French hospitals assessed pharmacist perception towards AMS, showed low confidence in applying pharmacodynamic parameters when adjusting antimicrobial doses or intervening during AMS rounds. ${ }^{6}$ Another study assessed pharmacists' knowledge in making AMS intervention and showed that only 3.5\% (13/368) of pharmacists were able to answer all assessment questions correctly. Moreover, less than half were confident in changing the antimicrobial spectrum in particular and overall junior pharmacists lack confidence in identifying AMS intervention compared with more experienced pharmacists. ${ }^{7}$ This study results highlighted the necessity to address gaps in undergraduate curricula in AMS and AMR field. Another study, in Qatar, indicated there were many gaps between AMS education and clinical practice, and recommended making AMS and AMR compulsory elements on undergraduate curricula. ${ }^{8}$ In Saudi Arabia, due to limited data regarding the knowledge and perceptions of AMS among healthcare students, a crosssectional study was conducted in Jazan University. This study showed similar results on the importance of including AMS in undergraduate curricula. Moreover, the highest percentage of the respondents would like to be trained and educated more on AMS and rated their knowledge level between average and poor. ${ }^{9}$ The current study was conducted to assess pharmacists' education and training on handling AMR, and also to assess the barriers that prevent pharmacists from handling AMR and the possible enablers that would help them to overcome the identified barriers.

\section{Methods}

\section{Study Design}

A cross-sectional design was used in this study. Data were collected using an online self-administered questionnaire (Figure 1).

\section{Population and Setting}

The study was conducted with registered pharmacists practicing in Ministry of Health hospital pharmacies in the Eastern region of Saudi Arabia. The total number of licensed pharmacists practicing in this sector is 314 .

\section{Sample Size and Sampling Procedure}

The sample size was determined based on the number of hospital pharmacists practicing in $\mathrm{MoH}$ hospitals (314) and calculated by using a Raosoft sample size calculator (http:// www.raosoft.com/samplesize.html) with a predetermined margin of error of 5\% and a confidence level of $90 \%$. In order to ensure study reliability and to minimize erroneous results, the target sample size was set at 164 pharmacists. A nonprobability convenience sampling method was chosen, including all $\mathrm{MoH}$ hospitals in the region. An official email containing an invitation letter was sent to the target 
Pharmacists' perceptions of handling antimicrobial resistance (AMR): A case study in Saudi Arabia

\section{Questionnaire}

Pharmacists perception towards handling antimicrobial resistance (AMR): A case study in Saudi Arabia

\section{Greetings}

If you are pharmacy intern, pharm-D intern, pharmacist, clinical pharmacy resident or post graduate pharmacist, you are invited to participate in our study aims to identify current status of pharmacist and clinical pharmacist in Saudi Arabia handling antimicrobial and intervening in infectious disease management at clinical practice setting

If you are willing to participate, then please kindly fill in the study questionnaire which will not take more than three minutes. There is no risk associated with this study and all the data is unidentifiable and will be stored in a safe settings

We extremely appreciate your time and effort

If you have any questions, please feel free to contact Dr. Zahra at email:

study.zalqamariat@gmail.com

Section 1

Demographic

Please answer following question

\section{What is your gender?}

Male

Female

2. What is your current position?

Pharmacy Intern (undergraduate)

Pharmacist/Senior or Consultant Pharmacist

Senior or Consultant Clinical Pharmacist

3. How long have you been practicing pharmacy?

$<1$ year

1-5 years

6-10 years

$>10$ years

\section{Is there an active Antimicrobial stewardship (AMS) program in your institution?}

Yes

No

Figure I Continue. 


\section{Were you involved in handling antimicrobial and intervene in infectious disease} management during COVID-19

Yes

No

\section{Section 2}

Enablers

Rate the statements regarding what have prepared and helped you handle antimicrobial and intervene in infectious disease management in clinical practice

\begin{tabular}{|c|c|c|c|c|c|}
\hline & $\begin{array}{l}\text { Strongly } \\
\text { disagree }\end{array}$ & Agree & Neutral & Agree & $\begin{array}{l}\text { Strongly } \\
\text { agree }\end{array}$ \\
\hline $\begin{array}{l}\text { Pharmacy } \\
\text { college } \\
\text { curriculum } \\
\text { has prepared } \\
\text { and helped } \\
\text { me handle } \\
\text { antimicrobial } \\
\text { and } \\
\text { intervene in } \\
\text { infectious } \\
\text { disease } \\
\text { management }\end{array}$ & & & & & \\
\hline $\begin{array}{l}\text { Pharmacy } \\
\text { rotation has } \\
\text { prepared } \\
\text { and helped } \\
\text { you handle } \\
\text { antimicrobial } \\
\text { and } \\
\text { intervene in } \\
\text { infectious } \\
\text { disease } \\
\text { management } \\
\text { in clinical } \\
\text { practice }\end{array}$ & & & & & \\
\hline $\begin{array}{l}\text { Years of } \\
\text { experience } \\
\text { has helped } \\
\text { me handle } \\
\text { antimicrobial } \\
\text { and } \\
\text { intervene in } \\
\text { infectious } \\
\text { disease } \\
\text { management } \\
\text { in clinical } \\
\text { practice }\end{array}$ & & & & & \\
\hline
\end{tabular}

Figure I Continue. 


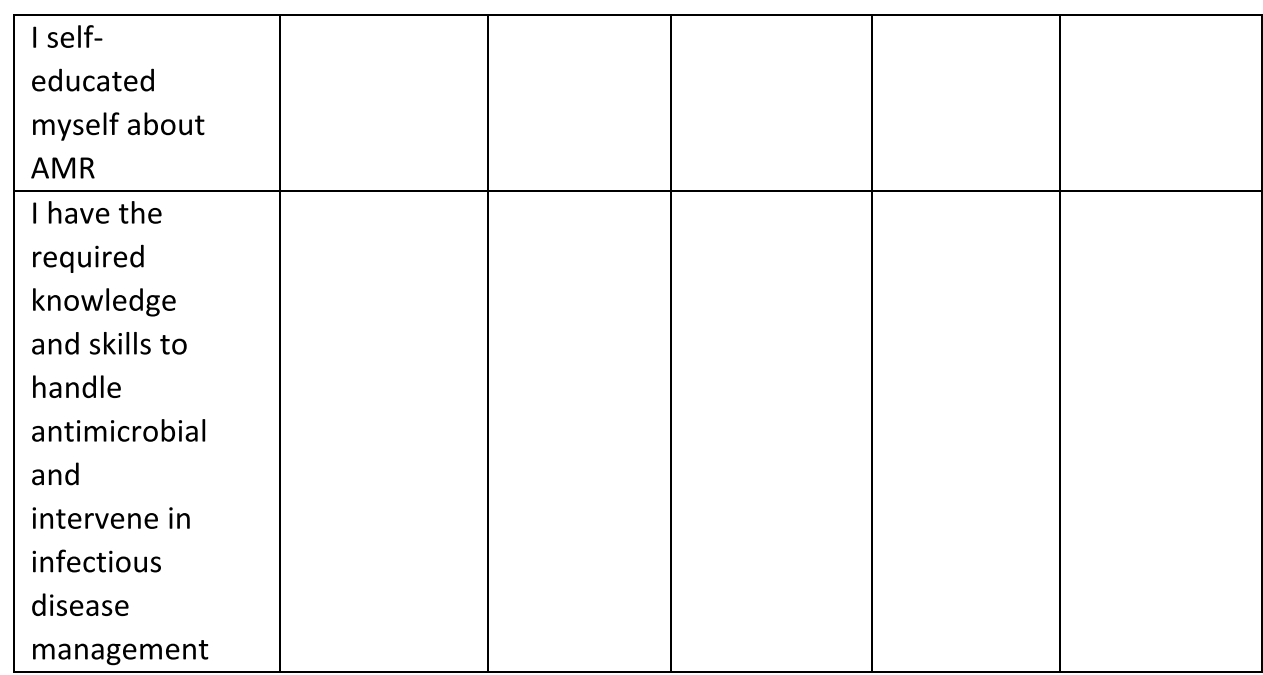

\section{Section 3}

Barriers

Rate the barriers faced by pharmacy personnel in handling antimicrobial and infectious disease management

\begin{tabular}{|l|l|l|l|l|l|}
\hline & $\begin{array}{l}\text { Not } \\
\text { relevant } \\
\text { relevance }\end{array}$ & Neutral & Relevant & $\begin{array}{l}\text { High } \\
\text { relevance }\end{array}$ \\
\hline $\begin{array}{l}\text { In-sufficient } \\
\text { background } \\
\text { with no } \\
\text { continuous } \\
\text { educational } \\
\text { and/or } \\
\text { training } \\
\text { program } \\
\text { provided by } \\
\text { institution }\end{array}$ & & & & & \\
\hline $\begin{array}{l}\text { Educational } \\
\text { and } \\
\text { training on } \\
\text { the field } \\
\text { not priority } \\
\text { for the } \\
\text { institution }\end{array}$ & & & & & \\
\hline $\begin{array}{l}\text { No time for } \\
\text { self- } \\
\text { learning on } \\
\text { the field }\end{array}$ & & & & & \\
\hline
\end{tabular}

Figure I Continue. 


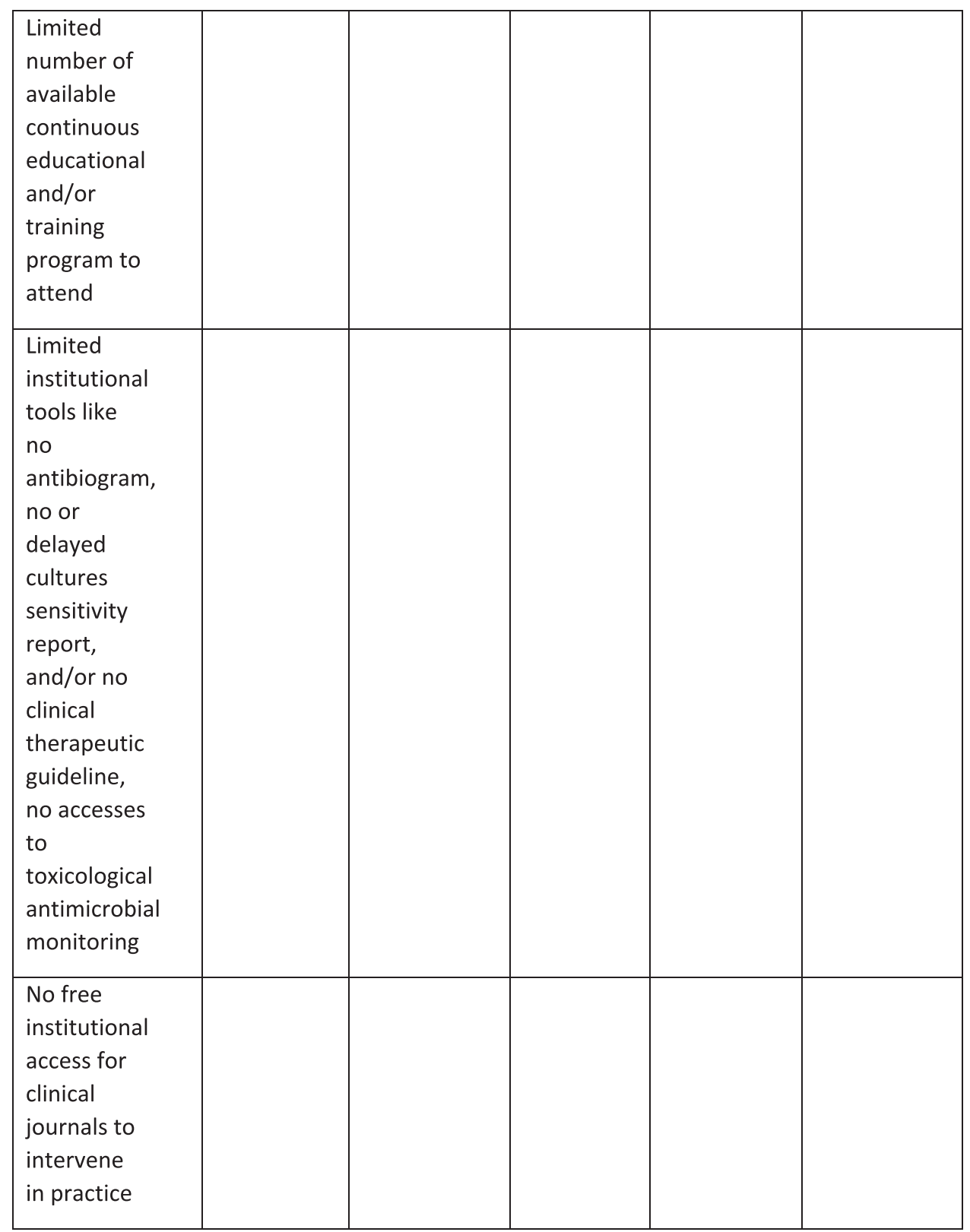

\section{Section 4}

Solutions

Rate the solution to eliminate barriers faced in handling antimicrobial and infectious disease management

Figure I Continue. 


\begin{tabular}{|c|c|c|c|c|c|}
\hline & $\begin{array}{l}\text { Not } \\
\text { relevant }\end{array}$ & $\begin{array}{l}\text { Low } \\
\text { relevance }\end{array}$ & Neutral & Relevant & $\begin{array}{l}\text { High } \\
\text { relevance }\end{array}$ \\
\hline $\begin{array}{l}\text { Organizing } \\
\text { frequent } \\
\text { continuous } \\
\text { educational } \\
\text { and/or } \\
\text { training } \\
\text { program by } \\
\text { institution }\end{array}$ & & & & & \\
\hline $\begin{array}{l}\text { Provide } \\
\text { institutional } \\
\text { funding } \\
\text { opportunitie } \\
\text { s for self- } \\
\text { learning } \\
\text { program on } \\
\text { the field }\end{array}$ & & & & & \\
\hline $\begin{array}{l}\text { Have the } \\
\text { time of self- } \\
\text { learning } \\
\text { counted on } \\
\text { working } \\
\text { hours Work } \\
\text { on } \\
\text { facilitating } \\
\text { clinical } \\
\text { practice by } \\
\text { providing } \\
\text { required } \\
\text { tools and } \\
\text { resources }\end{array}$ & & & & & \\
\hline $\begin{array}{l}\text { Have yearly } \\
\text { competency } \\
\text { evaluation } \\
\text { for } \\
\text { pharmacy } \\
\text { staff on the } \\
\text { field }\end{array}$ & & & & & \\
\hline
\end{tabular}

Figure I Pharmacists perception towards handling antimicrobial resistance (AMR): A case study in Saudi Arabia.

population via email. A total of 109 completed questionnaires were received, giving a response rate of $66.5 \%$.

\section{Data Collection Form}

The data collection tool was adapted from previous studies. ${ }^{1,8}$ The study authors who are expert in the field of AMR ie being an infectious disease clinical pharmacists and associate professor in Clinical pharmacy finalized the questionnaire. The questionnaire consisted of five domains: demographics/background information, enablers that helped in preparing pharmacists to handle AMR, barriers faced by pharmacy personnel in handling AMR and The possible strategies to overcome the identified barriers. The questionnaire was piloted with 10 hospital pharmacists who were representative of the target population to determine the language accuracy and the 
questionnaire structure. The results of the pilot study were not included in the results. The structured questionnaire was discussed, modified and approved based on the feedback received in the pilot. The questionnaire was finalized in the English language in the form of a self-administered web-based questionnaire.

\section{Inclusion Criteria}

Respondents were expected to be certified to practice pharmacy in Saudi Arabia, currently working as hospital pharmacists in an $\mathrm{MoH}$ hospital, have a minimum of a first degree or higher degree in pharmacy, and willing to participate in the study.

\section{The Exclusion Criteria}

Those pharmacists working in other pharmacy sectors including pharmaceutical companies, community pharmacy, academia and pharmaceutical regulation - were excluded from the study population.

\section{Statistical Analysis}

The collected data were cleared, entered and analyzed by using the Statistical Package for Social Sciences (SPSS) version 26.0 for Mac. Demographic and background information were described in terms of frequencies. The section entitled "Enablers that helped in preparing pharmacists to handle AMR" (5 items) and the section entitled "The impact of the COVID-19 pandemic on handling AMR" (3 items) used a Likert scale ranging from 1 (strongly disagree) to 5 (strongly agree), while "Barriers faced by pharmacy personnel in handling AMR" (6 items) as well as "Possible strategies to overcome the identified barriers" (5 items) used a Likert scale ranging from 1 (not relevant) to 5 (high relevance). Scale items were categorized into themes. The distribution of the scale is presented in percentages, using mean and SD. The internal consistency and reliability of the scales was assessed using Cronbach's alpha coefficient, with the minimum recommended level being 0.70 .

\section{Ethical Approval}

Ethical clearance was given by the Ethical Committee of Scientific Research, King Khalid University ECM\#20203214. All respondents were asked for their consent before participating in the study. All participants provided informed consent in accordance with the Declaration of Helsinki.

\section{Results}

Table 1 shows the pharmacists' demographics. A total of 109 participants were included in the study. Just under two thirds $(62.4 \%)$ of participants were female and the majority $(70.6 \%)$ worked as pharmacists. Just under half $(41.7 \%)$ had between 6 and 10 years of work experience. Three quarters $(74.3 \%)$ had antimicrobial stewardship in place and around the same number (73.4\%) were involved in handling infectious diseases management during the COVID-19 pandemic.

Table 2 shows the distribution of scores of the five statements regarding pharmacists' education and training in AMR. The responses ranged from 1 (strongly disagree) to 5 (strongly agree). Most items were neutral (3), indicating that pharmacists found that preparatory items/tasks pharmacy college curriculum, pharmacy rotation, years of experience and self-education to be natural, with a mean of 3.2 .

Table 3 shows the distribution of the scores of the five statements regarding barriers preventing pharmacists from handling AMR. The responses ranged from 1 (not relevant) to 5 (high relevance). All responses were skewed

Table I Background and Demographics

\begin{tabular}{|l|l|l|}
\hline & Frequency $\mathbf{~}$ & Percentage \% \\
\hline Gender & & \\
Male & 41 & 37.6 \\
Female & 68 & 62.4 \\
\hline Current status & & \\
Pharmacy intern undergraduate & 6 & 5.5 \\
Pharmacist & 77 & 70.6 \\
Senior or Consultant Clinical & 26 & 23.9 \\
Pharmacist & & \\
\hline Work experience in years & & \\
$<1$ & 11 & 10.1 \\
I-5 & 34 & 31.5 \\
6-I0 & 45 & 41.7 \\
$>10$ & 18 & 16.6 \\
\hline Availability of Antimicrobial & & \\
stewardship & & \\
Yes & 81 & 74.3 \\
No & 28 & 25.7 \\
\hline Involvement in handling infectious & & \\
disease management during & & \\
COVID-19 & 80 & \\
Yes & 29 & \\
No & & \\
\hline
\end{tabular}


Table 2 Distribution of Pharmacists' Education and Training Background Pertaining to Handling Antimicrobial and Intervening in Infectious Disease Management in Clinical Practice, from I (Strongly Disagree) to 5 (Strongly Agree)

\begin{tabular}{|c|c|c|c|c|c|c|c|c|}
\hline \multirow[t]{2}{*}{ Statement } & \multicolumn{5}{|c|}{ Distribution of Responses (\%) } & \multirow[t]{2}{*}{ Mean } & \multirow[t]{2}{*}{ SD } & \multirow[t]{2}{*}{ Skewness } \\
\hline & $\mathbf{I}$ & 2 & 3 & 4 & 5 & & & \\
\hline $\begin{array}{l}\text { Pharmacy college curriculum has prepared and helped me handle antimicrobial } \\
\text { and intervene in infectious disease management }\end{array}$ & 11 & 42.2 & 34.9 & 8.3 & 3.7 & 2.5 & 0.92 & 0.5 \\
\hline $\begin{array}{l}\text { Pharmacy rotation has prepared and helped me handle antimicrobial and } \\
\text { intervene in infectious disease management in clinical practice }\end{array}$ & 2.8 & 19.3 & 38.5 & 30.3 & 9.2 & 3.2 & 0.96 & -0.52 \\
\hline $\begin{array}{l}\text { Years of experience have helped me handle antimicrobial and intervene in } \\
\text { infectious disease management in clinical practice }\end{array}$ & 3.7 & 8.3 & 36.7 & 38.5 & 12.8 & 3.4 & 0.94 & -0.45 \\
\hline I self-educated about AMR & 4.6 & 13.8 & 18.3 & 39.4 & 22 & 3.5 & 1.1 & -0.63 \\
\hline $\begin{array}{l}\text { I have the required knowledge and skills to handle antimicrobial and intervene in } \\
\text { infectious disease management }\end{array}$ & 7.3 & 22 & 39.4 & 22 & 9.2 & 3.03 & 1.05 & 0.023 \\
\hline
\end{tabular}

Note: $I=$ strongly disagree, $2=$ agree, $3=$ neutral, $4=$ agree, $5=$ strongly agree.

Table 3 Distribution of Barriers Faced by Pharmacists in Handling AMR, Ranging from I (Not Relevant) to 5 (High Relevance)

\begin{tabular}{|l|l|l|l|l|l|l|l|l|}
\hline \multirow{2}{*}{ Statement } & \multicolumn{2}{|l|}{ Distribution of Responses (\%) } & \multirow{2}{*}{ Mean } & \multirow{2}{*}{ SD } & \multirow{2}{*}{ Skewness } \\
\cline { 2 - 6 } & $\mathbf{I}$ & $\mathbf{2}$ & $\mathbf{3}$ & $\mathbf{4}$ & $\mathbf{5}$ & & \\
\hline Insufficient background & 2.8 & 2.8 & 12.8 & 23.9 & 57.8 & 4.3 & 0.98 & -1.5 \\
\hline Education and training in the field not a priority for the institution & 4.6 & 7.3 & 22.9 & 26.6 & 38.5 & 3.9 & 1.1 & -0.79 \\
\hline No time for self-learning in the field & 5.5 & 9.2 & 11.9 & 22 & 51.4 & 4.04 & 1.2 & -1.1 \\
\hline $\begin{array}{l}\text { Limited number of available continuous educational and/or training programs to } \\
\text { attend }\end{array}$ & 7.3 & 10.1 & 22 & 22 & 38.5 & 3.7 & 1.2 & -0.68 \\
\hline $\begin{array}{l}\text { Limited institutional tools, like no antibiogram, no or delayed cultures sensitivity } \\
\text { report, and/or no clinical therapeutic guidelines, no access to toxicological } \\
\text { antimicrobial monitoring }\end{array}$ & 3.7 & 4.6 & 15.6 & 25.7 & 50.5 & 4.1 & 1.07 & -1.2 \\
\hline No free institutional access for clinical journals to intervene in practice & 1.8 & 10.1 & 9.2 & 20.2 & 58.7 & 4.2 & 1.09 & -1.3 \\
\hline
\end{tabular}

Note: $\mathrm{I}=$ not relevant, $2=$ low relevance, $3=$ neutral, $4=$ relevant, $5=$ high relevance.

towards five, indicating that participants found all the barriers - insufficient background, in-site education and training, limited time, limited CPD activities, limited educational tools, and no free access to relevant clinical journals - to be relevant, with a mean of 4.05 .

Table 4 shows the distribution of the scores of the five statements regarding enablers that would help pharmacists in handling AMR. The responses ranged from 1 (not relevant) to 5 (high relevance). All responses were skewed towards five, indicating that participants found all the enablers - CPD activities, funded educational programs, allowing time for selfeducation, accessible educational resources and tools and annual evolution of competencies - to be relevant, with a mean of 4.12 .

Table 5 presents the distribution of the variables being investigated. These scales are treated as continuous variables, ranging from 1 (strongly disagree) to 5 (strongly agree) for education and training preparation, and 1 (not relevant) to 5 (high relevance) for barriers preventing pharmacists from handing AMR and enablers to overcome the barriers. The mean values of the overall scales - education and training, barriers and enablers - were 3.24 .05 and 4.12, respectively. All scales had a Cronbach alpha coefficient greater than 0.7, indicating inter-item reliability. 
Table 4 Distribution of Enablers to Handling AMR, Ranging from I (Not Relevant) to 5 (High Relevance)

\begin{tabular}{|l|l|l|l|l|l|l|l|l|}
\hline Statement & \multicolumn{2}{|l|}{ Distribution of Responses (\%) } & \multirow{2}{*}{ Mean } & \multirow{2}{*}{ SD } & \multirow{2}{*}{ Skewness } \\
\cline { 2 - 5 } & $\mathbf{I}$ & $\mathbf{2}$ & $\mathbf{3}$ & $\mathbf{4}$ & $\mathbf{5}$ & & \\
\hline $\begin{array}{l}\text { Organizing frequent continuous educational and/or training programs by } \\
\text { institution }\end{array}$ & 0.9 & 6.4 & 8.3 & 37.6 & 46.8 & 4.2 & 0.9 & -1.3 \\
\cline { 1 - 5 } Provide institutional funding opportunities for self-learning program in the field & 3.7 & 2.8 & 9.2 & 21.1 & 63.3 & 4.4 & 1.01 & -1.8 \\
\hline Have the time for self-learning counted as working hours & 2.8 & 2.8 & 9.2 & 16.5 & 68.8 & 4.5 & 0.96 & -1.9 \\
\hline Work on facilitating clinical practice by providing required tools and resources & 2.8 & 2.8 & 7.3 & 29.4 & 57.8 & 4.4 & 0.9 & -1.8 \\
\hline Have annual competency evaluation for pharmacy staff in the field & 5.5 & 25.7 & 27.5 & 26.6 & 14.7 & 3.1 & 1.4 & -0.008 \\
\hline
\end{tabular}

Note: I= not relevant, $2=$ =low relevance, $3=$ neutral, $4=$ relevant, $5=$ high relevance.

Table 5 Distribution and Internal Consistency of Overall Scales

\begin{tabular}{|c|c|c|c|c|c|c|c|c|c|}
\hline \multirow[t]{2}{*}{ Description of Scale } & \multicolumn{5}{|c|}{ Distribution of Responses (\%) } & \multirow[t]{2}{*}{ Mean } & \multirow[t]{2}{*}{ SD } & \multirow[t]{2}{*}{ Skew } & \multirow[t]{2}{*}{ Cronbach Alpha } \\
\hline & $\leq \mathbf{I}$ & $\leq 2$ & $\leq \mathbf{3}$ & $\leq \mathbf{4}$ & $\leq \mathbf{5}$ & & & & \\
\hline Preparation & 0 & 8.3 & 18.3 & 7.3 & 100 & 3.2 & 0.75 & -0.074 & 0.73 \\
\hline Barriers & 0 & 1.8 & 6.4 & 5.5 & 100 & 4.05 & 0.92 & -0.99 & 0.896 \\
\hline Solutions & 0.9 & 0.9 & 1.8 & 11 & 100 & 4.12 & 0.78 & -1.8 & 0.847 \\
\hline
\end{tabular}

\section{Discussion}

AMR and its complications have been globally recognized and addressed as a threat. Thus, several global and national action plans have been proposed or implemented. The KSA 2017 National Action Plan is structured based on the WHO's objectives to eliminate AMR. The plan has proven its positive impact in many aspects, particularly in reducing the rate of AMR through implementing AMS and restricting antimicrobial sales without prescription. For example, AMS had resulted in a reduction of both AMR and antibiotics utilization within one year of implementation in Saudi Medical City ${ }^{10}$ and antimicrobial sales restriction in community pharmacies ended with a 50\% reduction in sales (Almeleebia et al 2020). Also, the KSA $\mathrm{MoH}$ has been working to improve professionals' understanding of AMR as one of the WHO's objectives by launching E-learning educational programs and recommending that academics teach AMR in undergraduate curricula. $^{2}$ Pharmacists are a core element of AMS and a major stakeholders in healthcare system and profession. ${ }^{4}$ Thus, empowering pharmacists' knowledge and skills to be capable of handling infectious diseases management will surely help combat AMR. This study focused on the perceptions of registered pharmacists working in $\mathrm{MoH}$ hospitals in the eastern province of KSA with regard to AMR as data on this aspect was rare. It also aimed to ascertain the barriers faced by pharmacists and their suggestions for eliminating these barriers. The majority of respondents in this study had been involved in clinical practice for more than a year. The highest percentage of pharmacists had worked between 6 to 10 years, which may be considered a sufficient time period to have quite clear perceptions and be able to list the barriers they face. Also, as approximately three quarters of respondents indicated that AMS was active in their placements and their involvement in handling infectious disease management during the COVID 19 pandemic, the results may represent the main barriers and show the important enablers to overcome them.

Pharmacists' responses were neutral when ranking pharmacy college curriculum, pharmacy rotation, years of experiences and self-education as preparatory items to handling antimicrobial and intervening in infectious disease management. However, the greatest percentage of pharmacists - that is, $42 \%$ - ranked pharmacy college curriculum as having low impact. It seems that pharmacy rotation and work experience may help more in preparation. Moreover, despite the same percentage (22\%) of pharmacists classifying themselves as having and the others not having the required knowledge and skills to handle antimicrobial and intervene in infectious disease management, a greater percentage (nearly 60\%) pointed 
to insufficient background as a barrier. This may be a reason for supporting the lower ranking of pharmacy college curriculums as preparatory elements. A quantitative structured interview survey of 46 leaders within and outside the pharmaceutical industry listed some threats to the pharmacy profession and practice discipline. About $23 \%$ of the leaders listed the failure of pharmacy schools to modify education and training to meet future needs as a challenge, and approximately $25 \%$ described pharmacists as unprepared to deal with future changes. Also, patient management skills were identified as an issue in pharmacy education and training to prepare graduate pharmacists for the future by $45 \%$ of leaders. This was followed by more than quarter of respondents indicating that leadership and management training, data analytics and curriculum innovation being adapted to change are other issues. ${ }^{11}$ Another study assessed pharmacists AMS knowledge also clearly highlighted the gap in undergraduate curricula regarding this subject. ${ }^{7}$ Thus, it may be suggested that pharmacy colleges curriculum content of infectious diseases such as AMR and AMS be assessed by qualified and experienced pharmacists in the field, from both clinical practice and academia. Also, the $2017 \mathrm{KSA}$ $\mathrm{MoH}$ recommendation to pharmacy colleges should be monitored, evaluated, improved and studied. Furthermore, the results of this study indicate that insufficient background may be precipitated by other factors, like a limited number of CPD and/or training programs, as well as the low priority of this subject in educational institutions or practice plans. The negative impact of these factors could worsen when there is limited time for selflearning, as this was considered a big barrier by about half of the pharmacists. Moreover, $58.9 \%$ of pharmacists indicated that institutions lacked free access to relevant clinical journals and this might make it difficult to keep updated, and to handle complex or rare cases in the field. Almost three quarters of pharmacists suggested that selflearning time be counted as working hours and around $63 \%$ supported the need for institutional funding opportunities for self-learning programs. Online courses can be one tool of self-learning that have shown its effectiveness in knowledge and skills improvement. For instance, one systematic review and meta-analysis assessed the impact of e-learning on pharmacy education, including 17 studies for the review. All the studies reported a tremendous improvement in knowledge after e-learning. Also, studies have indicated that e-learning is equally effective as traditional learning and has a positive impact on pharmacists' attitudes. $^{12}$ As the pharmacist's work is naturally busy, along with the entire life environment, counting selflearning time as working hours might encourage pharmacists to learn and improve their knowledge and skills. This may not be beneficial for pharmacists only, but also for the institutions. It may help institutions build their educational plans and prioritize needs. It may not facilitate institution educational finance only, but it may save institutions money because of the avoidance of expense on employees' travel. Both recommendations may be studied as one of the strategies to improve staff education and training levels and impact an institution's finances.

It has been shown that education and training are more effective when they are continuous. ${ }^{13}$ In this study, about half of the pharmacists suggested they were in favor of frequent and continuous educational and/or training programs given by clinical institutions. Also, a quarter of pharmacists agreed that an annual competency assessment in the field might be effective. This could also be a tool for measuring the effect of the chosen interventions. Thus, clinical institutions are encouraged to participate in building the future of the pharmacy profession and clinical practice through conducting continuous educational and training activities, as well as by supporting staff selflearning. Certainly, qualified and more expert pharmacists will improve the training experience for undergraduates, graduate pharmacy students and newly-hired employees, and help eliminate the gaps between academia and clinical practice.

Finally, the last barrier nominated by half of the pharmacists was limited resources to facilitate clinical practice, like the availability of antibiograms, therapeutic guidelines, cultural sensitivity reports or access to toxicology antimicrobial monitoring, which are all necessary elements for AMS. These elements are widely recommended and found to essentials by the WHO in the Antimicrobial stewardship programmes in health-care facilities in lowand middle-income countries by the WHO practical toolkit that was published in 2019. This barrier could affect AMS implementation and daily clinical practice, even if staff background, knowledge and skills were advanced. A high percentage $(57.8 \%)$ of pharmacists strongly agreed with the necessity of these resources in clinical practice.

This investigation has some limitation. Although efforts were made to increase the response rate by sending multiple reminders to the target population, but the response did not increase. 


\section{Conclusion}

In summary, this was a cross-sectional survey study to show the perceptions of hospital pharmacists with regard to AMR and the handling of infectious disease management. It listed some of the barriers such as lack of time, lack of continuing education programs, tight budgets assigned educational activities and enablers such as allocating time and budget for relevant continuing education activities as well as providing pharmacists with required tools and resources for overcoming them and consequently improving the current and future pharmacy academia and clinical practice.

\section{Disclosure}

The authors report no conflicts of interest in this work.

\section{References}

1. Sakeena MHF, Bennett AA, Mclachlan AJ. Enhancing pharmacists , role in developing countries to overcome the challenge of antimicrobial resistance: a narrative review. Antimicrob Resist Infect Control. 2018;7(1):1-11. doi:10.1186/s13756-018-0351-z

2. World Health Organization. Kingdom of Saudi Arabia national action plan on combating antimicrobial resistance; 2017. Available from: https://www.who.int/publications/m/item/kingdom-of-saudi-arabianational-action-plan-on-combating-antimicrobial-resistance. Accessed October 18, 2021.

3. Almeleebia TM, Alhifany AA, Almutairi F, Alshibani M, Alhossan AM. Regulating antimicrobial sales in Saudi Arabia: achievements and challenges. Int J Clin Pract. 2021;75(4):e13833. doi:10.1111/ijcp.13833

4. Gallagher JC, Justo JA, Chahine EB, et al. Preventing the post-antibiotic era by training future pharmacists as antimicrobial stewards. Am J Pharm Educ. 2018;82(6):6770. doi:10.5688/ajpe6770
5. Tang KL, Teoh TF, Ooi TT, et al. Public hospital pharmacists' perceptions and knowledge of antibiotic use and resistance: a multicenter survey. Antibiotics. 2020;9(6):311. doi:10.3390/ antibiotics 9060311

6. Weier N, Tebano G, Thilly N, Demoré B, Pulcini C, Zaidi STR. Pharmacist participation in antimicrobial stewardship in Australian and French hospitals: a cross-sectional nationwide survey. J Antimicrob Chemother. 2018;73(3):804-813. doi:10.1093/jac/ dkx435

7. Khumra S, Mahony AA, Bergen PJ, Page AT, Elliott RA. Exploring the practice, confidence and educational needs of hospital pharmacists in reviewing antimicrobial prescribing: a cross-sectional, nationwide survey. BMC Med Educ. 2021;21(1):235. doi:10.1186/s12909-02102664-1

8. Nasr ZG, Higazy A, Wilbur K. Exploring the gaps between education and pharmacy practice on antimicrobial stewardship: a qualitative study among pharmacists in Qatar. Adv Med Educ Pract. 2019;10:287-295. doi:10.2147/AMEP.S198343

9. Tripathi R, Albarraq AA, Makeen HA, Alqahtani SS, Tripathi P, Pancholi SS. Knowledge and perceptions of antimicrobial stewardship program among health-care students in Saudi Arabia; 2020. Available from: https://www.saudijhealthsci.org/article.asp?issn= $2278-0521$; year $=2020 ;$ volume $=9 ;$ issue $=2 ;$ spage $=122 ;$ epage $=129$; aulast=Tripathi. Accessed October 10, 2021.

10. Alghamdi S, Berrou I, Bajnaid E, et al. Antimicrobial stewardship program implementation in a Saudi Medical City: an exploratory case study. Antibiot Basel Switz. 2021;10(3):280. doi:10.3390/ antibiotics 10030280

11. Papadopoulos V, Goldman D, Wang C, Keller M, Chen S. Looking ahead to 2030: survey of evolving needs in pharmacy education. Pharm Basel Switz. 2021;9(1):59. doi:10.3390/ pharmacy 9010059

12. Salter SM, Karia A, Sanfilippo FM, Clifford RM. Effectiveness of E-learning in pharmacy education. Am J Pharm Educ. 2014;78(4):83. doi:10.5688/ajpe78483

13. Filipe HP, Silva ED, Stulting AA, Golnik KC. Continuing professional development: best practices. Middle East Afr J Ophthalmol. 2014;21(2):134-141. doi:10.4103/0974-9233.129760
Infection and Drug Resistance

\section{Publish your work in this journal}

Infection and Drug Resistance is an international, peer-reviewed openaccess journal that focuses on the optimal treatment of infection (bacterial, fungal and viral) and the development and institution of preventive strategies to minimize the development and spread of resistance. The journal is specifically concerned with the epidemiology of antibiotic resistance and the mechanisms of resistance development and diffusion in both hospitals and the community. The manuscript management system is completely online and includes a very quick and fair peerreview system, which is all easy to use. Visit http://www.dovepress.com/ testimonials.php to read real quotes from published authors. 